\title{
Protection of Vaginal Epithelial Cells with Probiotic Lactobacilli and the Effect of Estrogen against Infection by Candida albicans
}

\author{
R. Doug Wagner, Shemedia J. Johnson, Danielle R. Tucker \\ Microbiology Division, National Center for Toxicological Research, Jefferson, USA \\ Email: doug.wagner@fda.hhs.gov
}

Received April 9, 2012; revised May 11, 2012; accepted May 19, 2012

\begin{abstract}
Some probiotic strains of lactobacilli appear to be protective against vulvovaginal candidiasis. The vaginal epithelial cell line (VK2 E6/E7) was used as a model to assess the protective mechanisms of probiotic lactobacilli for cells challenged with Candida albicans. Co-culture of VK2 cells with Lactobacillus rhamnosus GR-1 and Lactobacillus reuteri RC-14 prior to $C$. albicans challenge showed reduced adherence of $C$. albicans to the VK2 cells and inhibition of $C$. albicans growth. $\mathrm{H}_{2} \mathrm{O}_{2}$ concentrations of $0.3 \mu \mathrm{g} / \mathrm{ml}$, produced by lactobacilli and estrogen-primed VK2 cells, were inhibitory to C. albicans growth. C. albicans growth was also inhibited by $10 \mu \mathrm{g} / \mathrm{ml}$ lactic acid. C. albicans infection was increased by $17 \beta$-estradiol through induction of hyphal germination. L. reuteri RC-14, but not L. rhamnosus GR-1, $\mathrm{H}_{2} \mathrm{O}_{2}$, or lactic acid inhibited estrogen-stimulated hyphal germination. The results of this study support a role for $\mathrm{H}_{2} \mathrm{O}_{2}$ and lactic acid from probiotic bacteria in vaginal epithelial protection from candidiasis and a role for $17 \beta$-estradiol in the disease by induction of $C$. albicans hyphal germination.
\end{abstract}

Keywords: Probiotic; Epithelial Cells; Candidiasis; Estrogen; Candida albicans

\section{Introduction}

The vaginal microbiota is one of the first lines of defense against vulvovaginal candidiasis (VVC). The cultivable normal vaginal microbiota is predominantly populated by Lactobacillus iners, Lactobacillus jensenii, and Lactobacillus crispatus [1], which tend to suppress growth of other bacterial species by production of lactic acid and antimicrobial products [2]. The low $\mathrm{pH}$ is considered a result of microbial metabolic products (mostly lactic acid) of glycogen, which is produced by vaginal epithelial cells [3]. During menses, the composition of the vaginal microbiota is destabilized [4] and it is at that time that probiotic lactobacilli may have a role to play in maintenance of the barrier to C. albicans infection. Although numerous strains of lactobacilli have been tested as probiotics as replacements for commensal bacterial resistance to VVC, many are not effective [5]. Some in vivo experiments have shown that $L$. rhamnosus GR-1 and L. reuteri RC-14 may be effective treatments for VVC [6]. If they are effective, their value may be in the production of $\mathrm{H}_{2} \mathrm{O}_{2}$, which is only produced by some strains of Lactobacillus spp. [7]. Adherence to the VK2 cells may also be a protective factor of these putative effective strains. For example, in one study, the probiotic effects of one
Lactobacillus sp. strain that inhibited C. albicans growth was associated with being strongly adherent to VK2 (E6/E7) vaginal epithelial cells [8].

Estrogens appear to affect both the infectivity of C. albicans and the recruitment of host defenses. Although $C$. albicans colonizes the vaginal tract as a commensal organism most of the time, conventional wisdom says that it can change to a virulent, invasive state by a mechanism that is still not clearly understood [2]. This process appears to be enhanced during the luteal phase of the menstrual cycle when there is a localized high estrogen concentration, which can also occur during high estrogen contraceptive use [2]. Some hormonal contraceptives induce epithelial hyperplasia in the vaginal tissues, even greater than normally occurs during the luteal phase of the menstrual cycle [9]. The presence of estrogen binding proteins expressed by $C$. albicans appears to be specific for estrogen and induces vaginal colonization in a rat model [10]. In vitro cell culture experiments show that estrogen causes a reduction in the transepithelial electrical resistance (TEER) of differentiated vaginal epithelial cell monolayers, which indicates a reduction in tight junctions between cells [11]. The loss of tight junctions under the control of estrogen could provide an increased opportunity for Candida sp. to invade vaginal tissue. 
Additional evidence for the role of estrogen in VVC has been shown in animal experiments, where it may have promoted germination of $C$. albicans and increased infection of the cornified vaginal epithelial tissues [12]. Thus, estrogen is an important factor affecting both fungal infectivity and the barrier functions of the vaginal epithelium.

The recurrent use of antifungal agents for VVC is a matter of concern as a selective pressure for the proliferation of drug-resistant strains of yeast [13]. Probiotic treatments may be an alternative or adjunct to antimicrobial drug use. The present study was done to evaluate effects of probiotic lactobacilli on VVC at the point of fungal contact with epithelial cells. The effects probiotic lactobacilli had on VE2 cells and C. albicans, which include fungal growth inhibition, cellular adhesion, $\mathrm{H}_{2} \mathrm{O}_{2}$ production, and $\mathrm{pH}$ modification, were evaluated. It was then of interest to establish whether probiotic lactobacilli have an effect on epithelial cell resistance to C. albicans, and how that effect is mediated and to establish whether estrogen has an influence on these processes.

\section{Methods}

\subsection{Microbial Strains and Growth Conditions}

Candida albicans strain B 311 (ATCC 32354) was grown aerobically overnight in Sabouraud's dextrose broth (Thermo Fisher Scientific, Houston, TX) at $37^{\circ}$ C. Lactobacillus rhamnosus GR-1 ${ }^{\circledR}$ and Lactobacillus reuteri $\mathrm{RC}-14^{\circledR}$, which were investigated because they are used in commercial vaginal probiotic products, (provided by Dr. Gregor Reid, Urex Bioscience, London, Ontario) were grown in anaerobic MRS broth (Thermo Fisher Scientific) at $35^{\circ} \mathrm{C}$.

\subsection{Culture and Microbial Challenge of VK2 Cell Line}

The vaginal epithelial cell line VK2 E6/E7 (CRL-2616, American Type Culture Collection, Rockville, MD.) was seeded at $5 \times 10^{5}$ cells $/ \mathrm{ml}$ and grown to confluence on 35 $\mathrm{mm}$ polyester inserts $[14,15]$ in Keratinocyte-Serum Free medium (K-SFM) containing $5 \mathrm{ng} / \mathrm{ml}$ recombinant epidermal growth factor and $50 \mu \mathrm{g} / \mathrm{ml}$ bovine pituitary extract (Invitrogen Corporation, Grand Island, NY) and primed with a physiological $10 \mathrm{nM}$ concentration of 17 $\beta$-estradiol in the basolateral medium [16]. Genital tract secretions (GTS) medium [17] was used on the apical side of the VK2 cell monolayers. The cells were grown at $37^{\circ} \mathrm{C}$ with a $5 \% \mathrm{CO}_{2}$ atmosphere and $100 \%$ humidity. Confluence, polarization, and differentiation of the VK2 cell monolayers were assessed by measurement of TEER with an EVOM device (World Precision Instruments, Inc., Sarasota, FL). Probiotic lactobacilli were added at 1 $\times 10^{7} \mathrm{CFU} / \mathrm{ml}$ to the apical culture chambers 4 hours before 18 hour challenge with $2 \times 10^{6} \mathrm{CFU} / \mathrm{ml} \mathrm{C}$. albicans. The experimental groups compared in this study were: 1) VK2 cells grown 18 hours with K-SFM medium on the basolateral sides and GTS medium on the apical sides of the culture inserts; 2) VK2 cells cultured in the same media and challenged 18 hours on the apical side with $2 \times 10^{6} \mathrm{CFU} C$. albicans; 3) VK2 cells with $10 \mathrm{nM}$ $17 \beta$-estradiol added to the basolateral medium; 4) VK2 cells with $10 \mathrm{nM} 17 \beta$-estradiol added to the basolateral medium and challenged on the apical side with $2 \times 10^{6}$ CFU C. albicans; 5) VK2 cells cultured with $1 \times 10^{7}$ CFU of both Lactobacillus strains on the apical side, and 6) VK2 cells cultured with $10 \mathrm{nM} 17 \beta$-estradiol added to the basolateral medium and pre-incubated 4 hours with 1 $\times 10^{7} \mathrm{CFU}$ of both Lactobacillus strains on the apical side before apical challenge with $2 \times 10^{6} \mathrm{CFU} \mathrm{C}$. albicans. The final incubations were 18 hours after C. albicans challenge.

\subsection{Effects of Treatments on Trans-Epithelial Electrical Resistance}

Differences in nutritional content of K-SFM and GTS to be used on the basolateral and apical sides, respectively, of the cell monolayers prompted the need to evaluate growth and stability of the VK2 cells and microbes in each medium. A 24-well plate of VK2 cells seeded at $5 \times$ $10^{5}$ cells $/ \mathrm{ml}$ on polycarbonate inserts in complete K-SFM was grown to confluence and maximal TEER at 7 days after plating. The K-SFM apical chamber media in 6 wells was replaced with GTS and grown with media changes every two days. Six wells were set up with GTS


up with K-SFM and $17 \beta$-estradiol. The monolayers were observed and TEER was measured daily. After a week, the cells were harvested from the inserts with trypsin/EDTA (Invitrogen) treatment and the numbers of viable and non-viable cells were counted in a hemacytometer using trypan blue stain. The effects of VK2 cell co-culture with microbes were assessed in the same manner.

\subsection{Effects of $\mathrm{H}_{2} \mathrm{O}_{2}$ and Lactic Acid on Growth of Microbes}

$50 \mu \mathrm{l}$ aliquots of an 18-hour C. albicans culture in Sabouraud's dextrose broth was diluted into $250 \mu \mathrm{l}$ of GTS medium containing serial dilutions of $\mathrm{H}_{2} \mathrm{O}_{2}$ or lactic acid (Sigma Chemical Co., St. Louis, MO) into wells of a 100-well honeycomb plate (Growth Curves, USA, Haverhill, MA) sealed with vinyl tape. The plates were incubated with shaking at 300 RPM and at a temperature of $37^{\circ} \mathrm{C}$ in a Bioscreen $\mathrm{C}$ instrument (Growth Curves) that recorded optical densities of growth in the wells at 15 
minutes intervals for 18 hours using a broad band filter at wavelengths of 420 - $580 \mathrm{~nm}$. Growth curves were generated and growth rates were estimated with Norden Lab v. 7.2 software (Norden Logic Oy, Helsinki, Finland) and Prism v. 5.0 software (GraphPad Software, San Diego, CA).

\subsection{Estrogen Effects on $C$. albicans Growth and Morphology}

$50 \mu \mathrm{l}$ aliquots of an 18-hour C. albicans culture in Sabouraud's dextrose broth were diluted into $250 \mu \mathrm{l}$ of GTS medium containing $10 \mathrm{nM} 17 \beta$-estradiol or $10 \mathrm{mM}$ $\mathrm{ICI}_{182,780}$, or containing both compounds in wells of a 96-well assay plate. The same treatments were also evaluated in a honeycomb plate for growth curve analyses. There were 6 replicates per treatment group. The assay plates were incubated 18 hours in a $37^{\circ} \mathrm{C}$ incubator. The cultures were diluted 10-fold in Dulbecco's phosphate-buffered saline (Invitrogen) and $100 \mu$ samples were spread onto microscope slides with a Cytofuge 2 cytocentrifuge for 4 minutes at 2200 RPM (Statspin, Norwood, MA). The slides were stained with Gram's stain and fungal blastospores and hyphae were counted and averaged from 10 high power $(400 \times)$ microscopic fields.

Gram stains were also analyzed to compare inhibitory effects of $0.01 \mu \mathrm{g} / \mathrm{ml} \mathrm{H}_{2} \mathrm{O}_{2}, 2 \mu \mathrm{g} / \mathrm{ml}$ lactic acid, $1 \times 10^{7}$ $\mathrm{CFU} / \mathrm{ml}$ L. rhamnosus GR-1 or $L$. reuteri $\mathrm{RC}-14$, or a combination of $1 \times 10^{7} \mathrm{CFU} / \mathrm{ml}$ of both strains of lactobacilli. The results were compared as ratios of hyphae to blastospores. The $\%$ hyphae present in microscopic fields were determined as numbers of hyphae counted/numbers of hyphae + numbers of blastospores $\times 100$.

\subsection{Adherence of $C$. albicans and Lactobacilli to VK2 Cells}

A semiquantitative assay for adherence of lactobacilli to the VK2 cells was employed [7]. Confluent cultures of VK2 cells on polyester inserts (Thermo Fisher) were co-cultured with lactobacilli at a concentration of $1 \times 10^{7}$ $\mathrm{CFU} / \mathrm{ml}$, and challenged with $2 \times 10^{6} \mathrm{CFU} / \mathrm{ml}$ of the virulent $C$. albicans strain, as described [7]. After 18 hours incubation at $37^{\circ} \mathrm{C}$ in a $5 \% \mathrm{CO}_{2}$ atmosphere with $100 \%$ humidity, the culture inserts were rinsed four times with GTS medium and the polyester membranes with the VK2 cell monolayers were removed from the inserts. The membranes were fixed with $3.7 \%$ paraformaldehyde for 1 hour. The membranes were rinsed with GTS medium and the cells were stained with Gram's crystal violet solution. The average number of bacteria and yeast cells adhering to VK2 cells were counted in 10 random microscopic fields.

\subsection{Fungal Inhibition Assay}

The ability of the probiotic bacteria to inhibit growth of $C$. albicans B 311 was evaluated with a culture overlay technique [7]. Each Lactobacillus strain was diluted in MRS broth (Thermo Fisher) to $9 \times 10^{8} \mathrm{CFU} / \mathrm{ml}$ and spread in $20 \mathrm{~mm}$ bands across MRS agar plates and then grown 24 hours at $35^{\circ} \mathrm{C}$ in an anaerobic chamber (Coy Laboratories, Grass Lake, MI). The cultures were overlaid with melted YM agar (Thermo Fisher). The plates were swabbed with C. albicans B 311 in Sabouraud broth diluted to $1.5 \times 10^{8}$ $\mathrm{CFU} / \mathrm{ml}$, pre-incubated at $4^{\circ} \mathrm{C}$ for 4 hours to harden the agar, and then incubated overnight at $37^{\circ} \mathrm{C}$ aerobically. Inhibition of $C$. albicans growth was observed visually and scored semi-quantitatively as: $(-)$ no inhibition, $(+)$ partial growth inhibition over the lactobacilli, $(++)$ complete inhibition over the lactobacilli, or $(+++)$ complete inhibition over and beyond the band of lactobacilli [7].

\subsection{Production of $\mathrm{H}_{2} \mathrm{O}_{2}$ by Lactobacilli in Culture}

The amount of $\mathrm{H}_{2} \mathrm{O}_{2}$ produced by the lactobacilli in culture was measured with an iodometric method designed for determinations from bacterial cultures [18]. Lactobacillus spp. cultures $(20 \mathrm{ml})$ were grown in Rogosa broth (Thermo Fisher) 48 hours at $35^{\circ} \mathrm{C}$ anaerobically and centrifuged at $1800 \times g$ for 15 minutes. Technical duplicates of each control and blank (Rogosa broth) and 6 replicates from each Lactobacillus sp. culture supernatant were added $(50 \mu \mathrm{l})$ to $2 \mathrm{ml}$ of $\mathrm{HCl}, 0.2 \mathrm{ml}$ of $\mathrm{KI}, 0.2 \mathrm{ml}$ of 1 $\mathrm{mm}$ ammonium molybdate solution (Sigma), and $0.2 \mathrm{ml}$ of starch solution (Sigma), as described [18]. The optical absorbance was measured with a spectrophotometer at $570 \mathrm{~nm}$ wavelength and the standard curve from serial dilutions of $\mathrm{H}_{2} \mathrm{O}_{2}$ and concentrations of samples were determined.

\subsection{Production of $\mathrm{H}_{2} \mathrm{O}_{2}$ by Lactobacilli on VK2 Cell Monolayers}

The amounts of $\mathrm{H}_{2} \mathrm{O}_{2}$ produced by the lactobacilli applied to the apical sides of VK2 cell monolayers were measured with a chromagenic method designed to measure $\mathrm{H}_{2} \mathrm{O}_{2}$ concentrations in vaginal secretions [18]. The GTS medium from the apical chambers and K-SFM medium from the basolateral chambers conditioned by the lactobacilli were diluted in $0.01 \mathrm{M}$ sodium acetate, $\mathrm{pH}$ 4.5 , mixed with $0.01 \mathrm{mg} / \mathrm{ml}$ peroxidase (Sigma) and $20 \mu \mathrm{l}$ $o$-dianisidine solution (Sigma), and incubated at room temperature 10 minutes. The reactions were stopped with $40 \mu \mathrm{l}$ of $4 \mathrm{~N} \mathrm{HCl}$ and incubated 5 minutes at room temperature. Color development was measured in a plate reader (Perkin Elmer, Waltham, MA) at 405 nm. Concentrations were determined from a standard curve consisting 
of dilutions of a $30 \% \mathrm{H}_{2} \mathrm{O}_{2}$ stock solution (Sigma).

\subsection{0. $\mathrm{pH}$ in Cell-Conditioned Media from Apical and Basolateral Culture Chambers}

The PHR-146 Micro Combination $\mathrm{pH}$ Electrode from Lazar Research (Thermo Fisher) was used to measure $\mathrm{pH}$ levels in cell-conditioned media. After the 18 hour incubation of VK2 cells with the microbes, media was removed and saved from the inserts and the wells; both were centrifuged at $10,000 \times g$ for 2 minutes, and the $\mathrm{pH}$ of each supernatant was measured using the micro $\mathrm{pH}$ electrode.

\subsection{Analysis of Data}

Normally distributed results were analyzed for statistical significance by paired T-tests where appropriate and by Repeated Measures One-Way Analysis of Variance and Newman-Keuls post tests for multiple comparisons [19] with Prism v. 5.0 software (GraphPad Software). Statistical significance was defined by a $\mathrm{P}<0.05$.

\section{Results}

\subsection{Effects of Apical Growth Medium on VK2 Cell Monolayers and Microbes}

The environment surrounding vaginal epithelial cells in vivo is different on the apical and basolateral sides of the vaginal mucosa. The effect of the media surrounding the VK2 cells grown on culture inserts on monolayer stability was assessed. Over seven days of culture, confluent monolayers had increased TEER values from 32 to $48 \Omega$ $\mathrm{cm}^{2}$. No differences in trypan blue uptake or cell counts were observed. On the fourth and seventh days of culture, the TEER values in K-SFM were higher than in GTS.

When the fungi and bacteria were inoculated into GTS individually to test for differences in growth characteristics, the numbers of $C$. albicans cells increased from $2 \times$ $10^{6} \mathrm{CFU} / \mathrm{ml}$ to $5.3 \times 10^{7} \mathrm{CFU} / \mathrm{ml}$ overnight. Addition of $17 \beta$-estradiol to the medium increased the average number of $C$. albicans to $1.2 \times 10^{8} \mathrm{CFU} / \mathrm{ml}$. Growth curves of C. albicans in GTS had significantly increased slopes from $12.42 \pm 0.57$ to $17.96 \pm 0.87$ (average $\mathrm{R}^{2}=0.948$ and 0.945 , respectively). Slopes were determined by regression analysis with Prism software, over 18 hours' incubation. The lactobacilli did not increase in numbers overnight in GTS or GTS containing $17 \beta$-estradiol; however, they remained viable in GTS medium for 48 hours, since growth resumed after transfer to MRS medium.

\subsection{Effects of Microbes and 17 $\beta$-Estradiol on VK2 Cell Monolayer Integrity}

The presence of $C$. albicans appeared to increase the
TEER of the VK2 cell monolayers of most samples, but the effect was not statistically significant (Figure 1). When $17 \beta$-estradiol was incubated with the cells alone, there was a significant increase in TEER, but when VK2 cells were treated with $17 \beta$-estradiol and $C$. albicanschallenged, the TEER values were significantly reduced (Figure 1). The probiotic lactobacilli did not significantly alter the TEER values of VK2 cells alone or modify the reduced TEER values of VK2 cells treated with $17 \beta$-estradiol and challenged with $C$. albicans (Figure 1).

\subsection{Effects on $C$. albicans Growth by Soluble Factors from Lactobacilli}

Assays of probiotic mechanisms were performed to assess the ability of L. rhamnosus GR-1 and L. reuteri RC-14 to inhibit the growth and infectivity of the C. albicans B-311 strain. The fungal inhibition assay revealed that both Lactobacillus spp. strains were inhibitory to $C$. albicans growth, which was inhibited $2+$ by $L$. rhamnosus GR-1 and 3+ by L. reuteri RC-14 (data not shown) on the 4-point scale of Strus, et al. [7]. This corresponds to $L$. reuteri $\mathrm{RC}-14$ producing more soluble factors that diffuse further into the agar overlay to inhibit $C$. albicans growth than those produced by L. rhamnosus GR-1.

As assessed in this study, the production of $\mathrm{H}_{2} \mathrm{O}_{2}$ by lactobacilli is an inhibitory mechanism of fungal growth The amount of $\mathrm{H}_{2} \mathrm{O}_{2}$ produced by $L$. rhamnosus GR-1 and $L$. reuteri $\mathrm{RC}-14$ in culture supernatants averaged



Figure 1. The TEER in VK2 cell monolayers were increased by $17 \beta$-estradiol and decreased by the lactobacilli. The experimental groups were: (1) VK 2 cells; (2) VK2 cells $+C$. albicans; (3) VK2 cells + 17 $\beta$-estradiol; (4) VK2 cells + $17 \beta$-estradiol $+C$. albicans; (5) VK2 cells + probiotic lactobacilli; (6) VK2 cells $+17 \beta$-estradiol $+C$. albicans + probiotic lactobacilli. Measurements of TEER were taken 18 hours after $C$. albicans challenge (groups 2, 4, and 6) or 22 hours after addition of $17 \boldsymbol{\beta}$-estradiol and probiotic lactobacilli (groups 3,5). All data represent mean \pm standard error for 6 VK2 cell monolayers. The asterisks show means that are significantly different than group 1 by analysis of variance, $\mathrm{P}<0.05$ 
$12.5 \mu \mathrm{g} / \mathrm{ml}$. These $\mathrm{H}_{2} \mathrm{O}_{2}$ concentrations were 20-fold greater than $\mathrm{H}_{2} \mathrm{O}_{2}$ concentrations present in the apical GTS media from the VK2 cell cultures containing lactobacilli. This difference in $\mathrm{H}_{2} \mathrm{O}_{2}$ concentrations produced by the lactobacilli in anaerobic enriched media compared with an environment approximating the vaginal mucosa suggests that the Lactobacillus strains tested may not be as adaptable to that environment as normal vaginal isolates. The $\mathrm{H}_{2} \mathrm{O}_{2}$ concentrations in $\mathrm{VK} 2$ cell cultures with or without $17 \beta$-estradiol, and VK2 cell cultures challenged with $C$. albicans were not different (Figure 2A). Addition of $17 \beta$-estradiol to the $C$. albicans-challenged VK2 cell cultures yielded significantly increased $\mathrm{H}_{2} \mathrm{O}_{2}$ concentrations in the basolateral medium (Figure 2A).

The probiotic lactobacilli did not induce $\mathrm{H}_{2} \mathrm{O}_{2}$ production by VK2 cells, and did not appear to contribute significantly to $\mathrm{H}_{2} \mathrm{O}_{2}$ in the co-culture with VK2 cells and $C$. albicans (Figure 2A).

Production of $\mathrm{H}_{2} \mathrm{O}_{2}$ by VK2 cells was not expected, but the cells are known to produce soluble factors that inhibit Candida spp. [8]. The $\mathrm{H}_{2} \mathrm{O}_{2}$ concentration was also significantly elevated in the basolateral media from the $C$. albicans-challenged group containing $17 \beta$-estradiol and the probiotic lactobacilli.

The average $\mathrm{pH}$ of $\mathrm{VK} 2$ cell cultures was not significantly affected by overnight challenge with $C$. albicans or $17 \beta$-estradiol. Co-culture of VK2 cells with the lactobacilli significantly decreased the $\mathrm{pH}$, in both the apical and basolateral media (Figure 2B). The presence of $C$. albicans and $17 \beta$-estradiol modulated the low $\mathrm{pH}$ produced by the probiotic lactobacilli.

\subsection{Adherence of $C$. albicans and Lactobacilli to VK2 Cells}

C. albicans adhered to VK2 cell monolayers as hyphae and blastospores (Figure 3A). The lactobacilli also ap-

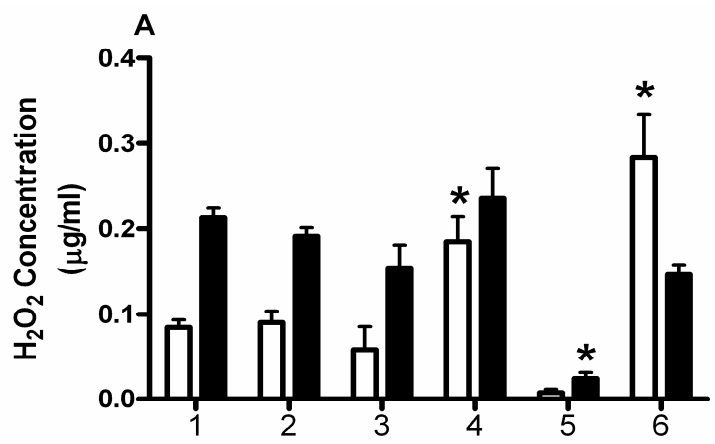

peared to adhere to the VK2 cells, and in their presence, C. albicans remained more in the blastospore form (Figure 3B). The numbers of adherent $C$. albicans on VK2 cells were significantly decreased in the presence of lactobacilli (Figure 3C).

Reduced adherence of $C$. albicans to VK2 cells in the presence of probiotic lactobacilli may be related to decreased $\mathrm{pH}$ resulting from acid production by the lactobacilli. This conclusion agrees with the observation by Gaffney et al., that lowered $\mathrm{pH}$ of vaginal fluids corresponds with reduced microbial adhesion to epithelial cell lines [20].

\subsection{Effects of $\mathrm{H}_{2} \mathrm{O}_{2}$ and Lactic Acid on Growth of Microbes}

Growth inhibitory concentrations of $\mathrm{H}_{2} \mathrm{O}_{2}$ and lactic acid for $C$. albicans, L. rhamnosus, and L. reuteri were determined using growth curve analyses. The inhibitory concentration of $\mathrm{H}_{2} \mathrm{O}_{2}$ on $C$. albicans was $0.3 \mu \mathrm{g} / \mathrm{ml}$ (Figure 4A). This was also the concentration maximally achieved by the lactobacilli co-cultured with VK2 cells. The inhibitory concentration of lactic acid on C. albicans growth was $10 \mu \mathrm{g} / \mathrm{ml}$ (Figure 4B).

Growth curves of L. rhamnosus GR-1 showed inhibitory concentrations of $50 \mu \mathrm{g} / \mathrm{ml} \mathrm{H}_{2} \mathrm{O}_{2}$ and $6 \mu \mathrm{g} / \mathrm{ml}$ lactic acid (Figure 5). The growth curves of $L$. reuteri $\mathrm{RC}-14$ showed inhibited growth at $2 \mu \mathrm{g} / \mathrm{ml} \mathrm{H}_{2} \mathrm{O}_{2}$ or $6 \mu \mathrm{g} / \mathrm{ml}$ lactic acid over an 18-hour time course (Figure 5).

Addition of $10 \mathrm{nM} 17 \beta$-estradiol increased C. albicans resistance to growth inhibition by $0.3 \mu \mathrm{g} / \mathrm{ml} \mathrm{H}_{2} \mathrm{O}_{2}$, but not $10 \mu \mathrm{g} / \mathrm{ml}$ lactic acid (Figure 6).

\subsection{Effects of Probiotic Lactobacilli and 17 $\beta$-Estradiol on C. albicans Morphology}

Addition of $10 \mathrm{nM} 17 \beta$-estradiol to $C$. albicans cultures

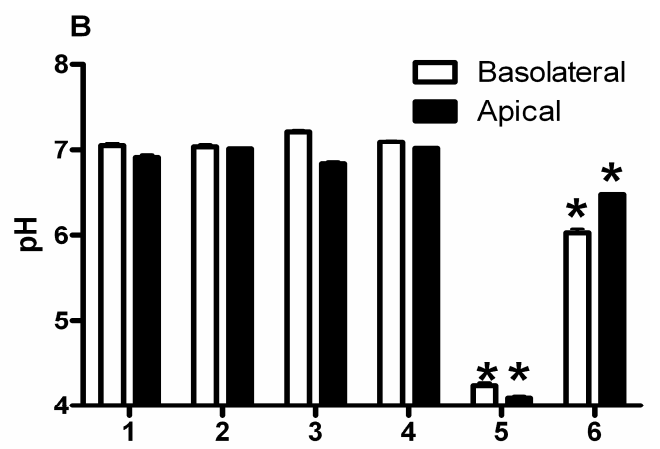

Figure 2. Effects of microbes and estrogen on concentrations of $\mathrm{H}_{2} \mathrm{O}_{2}$ and $\mathrm{pH}$ measurements in culture supernatants. (A) The $\mathrm{H}_{2} \mathrm{O}_{2}$ concentrations in $(\square)$ basolateral and $(\square)$ apical culture supernatants were measured by the chromagenic method; (B) The pH of basolateral and apical media were measured 18 hours after challenge with $C$. albicans and compared between the experimental groups. The experimental groups were: 1) VK 2 cells; 2) VK2 cells $+C$. albicans; 3) VK2 cells $+17 \beta$-estradiol; 4) VK2 cells $+17 \beta$-estradiol $+C$. albicans; 5) VK2 cells + probiotic lactobacilli; 6) VK2 cells $+17 \beta$-estradiol $+C$. albicans + probiotic lactobacilli. All data represent mean \pm standard error for 6 VK2 cell monolayers. The asterisks show means that are significantly different than group 1 by analysis of variance, $P<0.05$. 

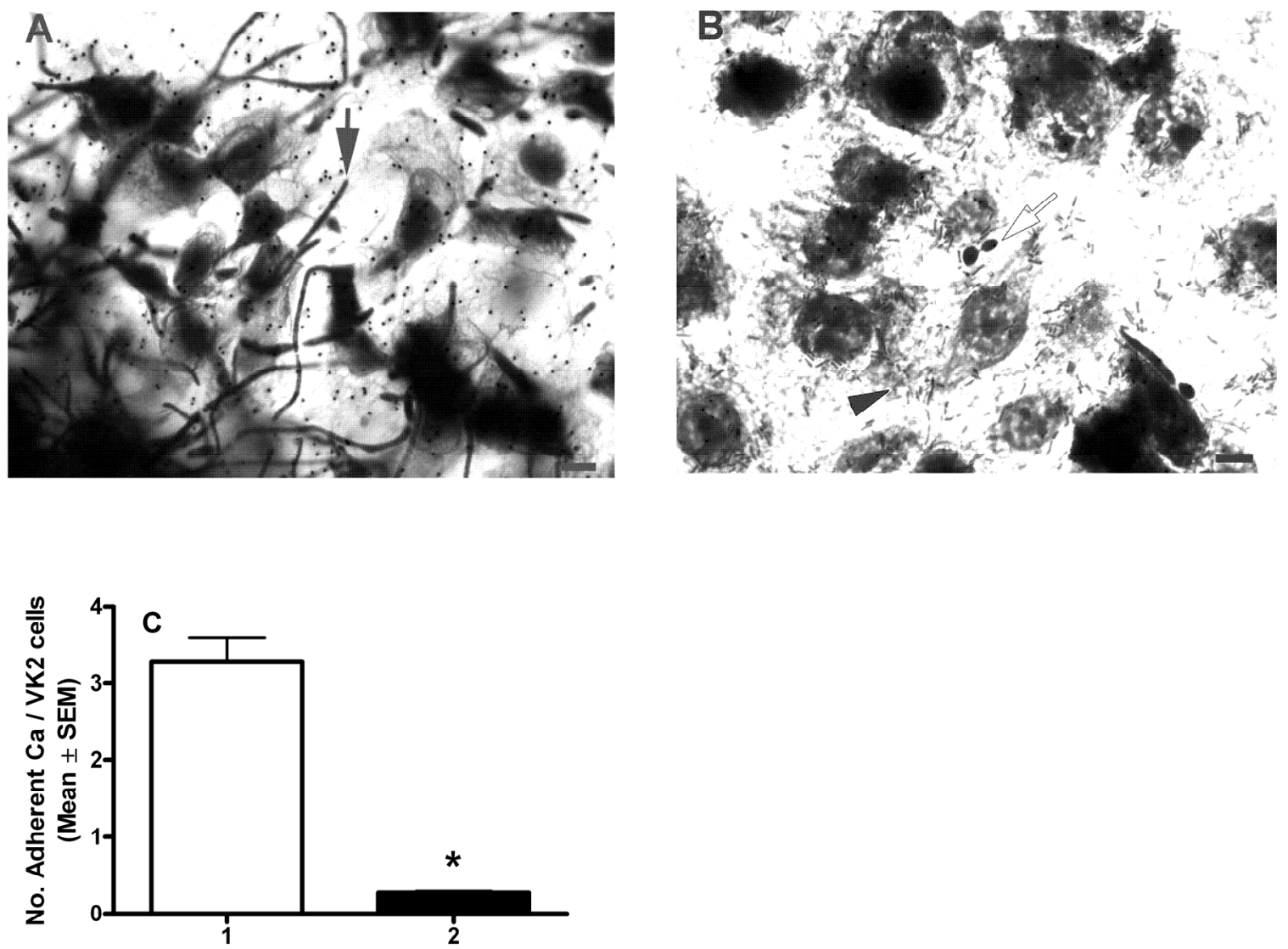

Figure 3. C. albicans and lactobacilli adhered to VK2 cells. Monolayers of VK2 cells were challenged with (A) C. albicans, and (B) probiotic lactobacilli and $C$. albicans in media containing $17 \beta$-estradiol overnight and then stained with crystal violet stain. The solid bars in the lower right corners of the photomicrographs indicate $10 \mu \mathrm{m}$ length, the solid arrow indicates $C$. albicans hyphae, the open arrow indicates $C$. albicans blastospores, and the arrowhead indicates lactobacilli. Average numbers of $C$. albicans cells adherent per VK2 cell from 10 high power microscopic fields $(400 \times)$ per sample were compared from 10 wells of each treatment group as shown in (C). The comparison groups were: 1) C. albicans-challenged VK2 cells and 2) VK2 cells treated with both Lactobacillus strains and challenged with $C$. albicans. The asterisk indicates statistically significant differences between means by the paired T-test, $P<0.05$.
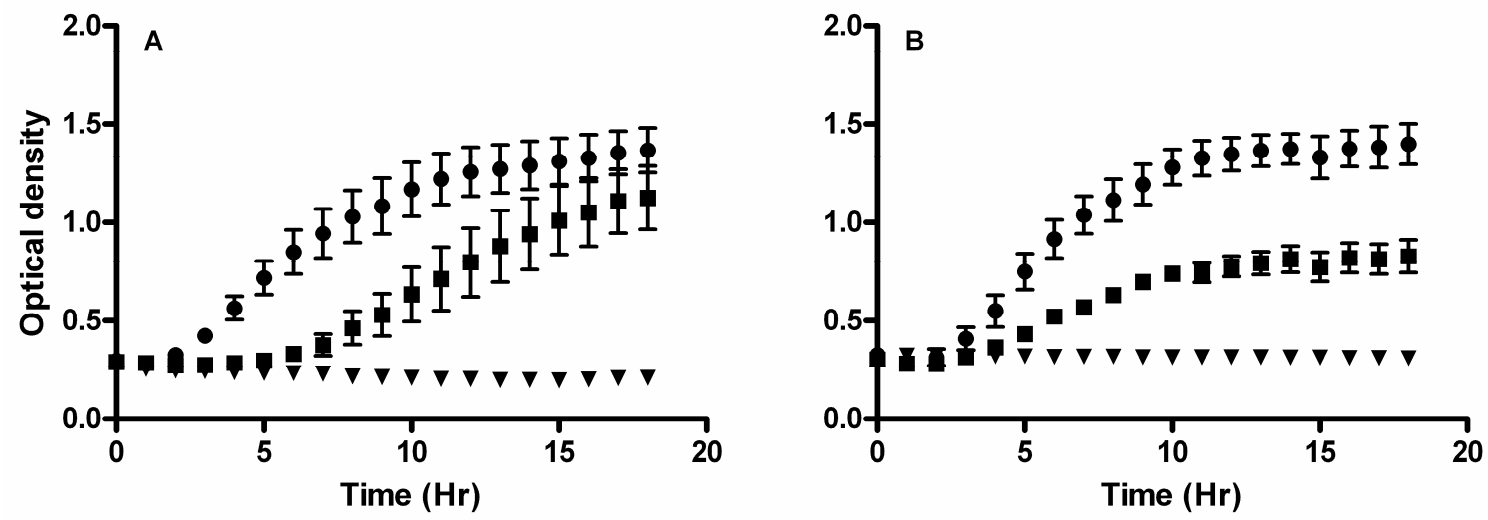

Figure 4. C. albicans growth was inhibited by $\mathrm{H}_{2} \mathrm{O}_{2}$ and lactic acid. Growth curves of $C$. albicans incubated with $(\mathrm{A}) \mathrm{H}_{2} \mathrm{O}_{2}$ or (B) lactic acid showing (O) uninhibited growth at $0.01 \mu \mathrm{g} / \mathrm{ml} \mathrm{H}_{2} \mathrm{O}_{2}$ or $2 \mu \mathrm{g} / \mathrm{ml}$ lactic acid, (ם) partially inhibited at $0.1 \mu \mathrm{g} / \mathrm{ml}$ $\mathrm{H}_{2} \mathrm{O}_{2}$ or $4 \mu \mathrm{g} / \mathrm{ml}$ lactic acid, and $(\nabla)$ inhibited growth at $0.3 \mu \mathrm{g} / \mathrm{ml} \mathrm{H}_{2} \mathrm{O}_{2}$ or $10 \mu \mathrm{g} / \mathrm{ml} \mathrm{lactic}$ acid over an 18-hour time course. All data represent mean \pm standard error $\mu \mathrm{g} / \mathrm{ml} \mathrm{H}_{2} \mathrm{O}_{2}$ or lactic acid for 6 samples. The means of the slopes of the uninhibited, inhibited, and partially inhibited growth curves, as derived from regression analyses, were significantly different from each other by analysis of variance, $P<0.05$. 

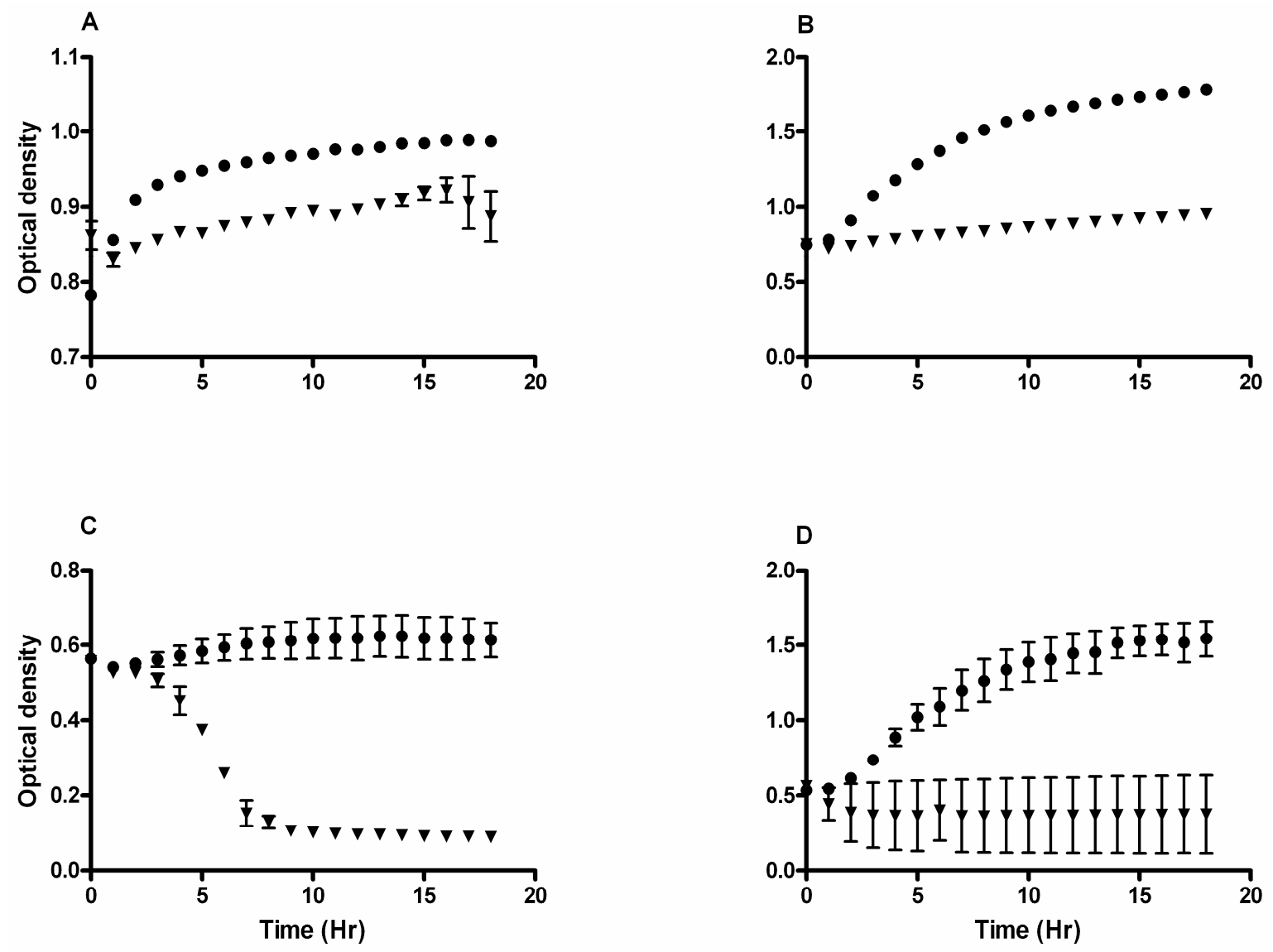

Figure 5. L. rhamnosus GR-1 and L. reuteri RC-14 growth inhibition by $\mathrm{H}_{2} \mathrm{O}_{2}$ and lactic acid. Growth curves of $L$. rhamnosus GR-1 incubated with (A) $\mathrm{H}_{2} \mathrm{O}_{2}$ or (B) lactic acid showing (๑) uninhibited growth at $2 \mu \mathrm{g} / \mathrm{ml} \mathrm{H}_{2} \mathrm{O}_{2}$ or $2 \mu \mathrm{g} / \mathrm{ml}$ lactic acid and ( $\nabla$ ) inhibited growth at $50 \mu \mathrm{g} / \mathrm{ml} \mathrm{H}_{2} \mathrm{O}_{2}$ or $6 \mu \mathrm{g} / \mathrm{ml}$ lactic acid over an 18-hour time course. Growth curves of $L$. reuteri RC-14 incubated with (C) $\mathrm{H}_{2} \mathrm{O}_{2}$ or (D) lactic acid showing (O) uninhibited growth at $0.3 \mu \mathrm{g} / \mathrm{ml} \mathrm{H}_{2} \mathrm{O}_{2}$ or $2 \mu \mathrm{g} / \mathrm{ml} \mathrm{lactic} \mathrm{acid} \mathrm{and} \mathrm{(} \nabla$ ) inhibited growth at $2 \mu \mathrm{g} / \mathrm{ml} \mathrm{H}_{2} \mathrm{O}_{2}$ or $6 \mu \mathrm{g} / \mathrm{ml}$ lactic acid over an 18-hour time course. All data represent mean \pm standard error $\mu \mathrm{g} / \mathrm{ml} \mathrm{H}_{2} \mathrm{O}_{2}$ or lactic acid for 6 samples. The means of the slopes of the inhibited and uninhibited growth curves were significantly different from each other, as derived from regression analyses, $P<0.05$.
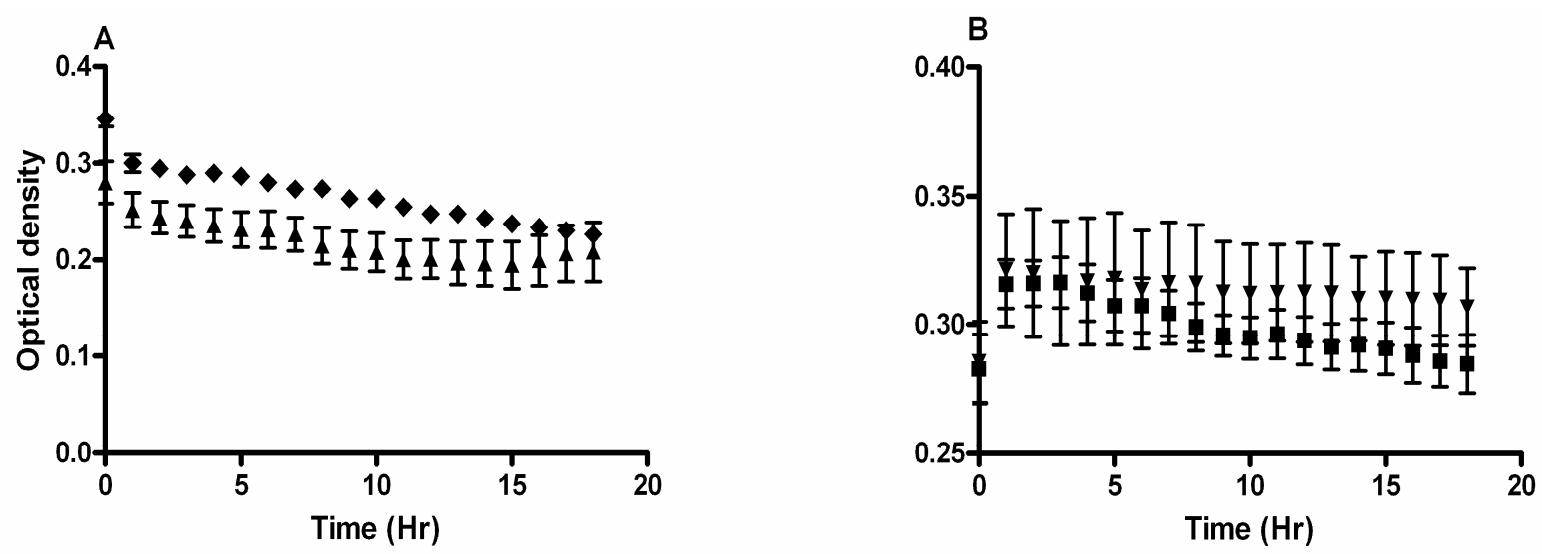

Figure 6. 17 $\beta$-estradiol affects $C$. albicans growth inhibition by $\mathrm{H}_{2} \mathrm{O}_{2}$. C. albicans was grown 18 hrs in GTS medium with ( $\Delta$ ) $0.3 \mu \mathrm{g} / \mathrm{ml} \mathrm{H}_{2} \mathrm{O}_{2},(\diamond) 0.3 \mu \mathrm{g} / \mathrm{ml} \mathrm{H}_{2} \mathrm{O}_{2}$ and $10 \mathrm{nM} 17 \beta$-estradiol, ( $\left.\nabla\right) 10 \mu \mathrm{g} / \mathrm{ml}$ lactic acid, or $(\square) 10 \mu \mathrm{g} / \mathrm{ml}$ lactic acid and $10 \mathrm{nM}$

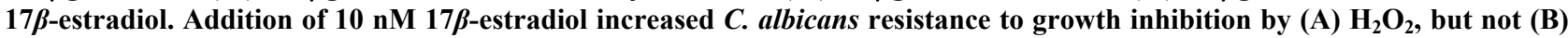
lactic acid. The slope of the growth curve of $C$. albicans grown with $0.3 \mu \mathrm{g} / \mathrm{ml} \mathrm{H}_{2} \mathrm{O}_{2}$ and $10 \mathrm{nM} 17 \beta$-estradiol was significantly greater than with $\mathrm{H}_{2} \mathrm{O}_{2}$ alone, as derived by regression analysis, $\mathrm{P}<\mathbf{0 . 0 5}$. All data represent mean $\pm \mathrm{standard} \mathrm{error} \mu \mathrm{g} / \mathrm{ml}$ $\mathrm{H}_{2} \mathrm{O}_{2}$ or lactic acid for 6 samples. 
was associated with an apparent increase in numbers of hyphal forms of the fungus (Figure 7). The percentages of hyphae in 10 microscopic fields per control or treatment increased significantly from $22 \%$ to $32 \%$, respectively, when $10 \mathrm{nM} 17 \beta$-estradiol was present during incubation.

The ability of $17 \beta$-estradiol to induce hyphal germination may be counteracted by cytotoxic molecules such as $\mathrm{H}_{2} \mathrm{O}_{2}$ and lactic acid. The probiotic lactobacilli may also have influenced $17 \beta$-estradiol induction of hyphal germination. To assess this, $C$. albicans was grown in GTS medium with or without $10 \mathrm{nM} 17 \beta$-estradiol and treated with $0.01 \mu \mathrm{g} / \mathrm{ml} \mathrm{H}_{2} \mathrm{O}_{2}, 2 \mu \mathrm{g} / \mathrm{ml}$ lactic acid, or with $1 \times$ $10^{7} \mathrm{CFU} / \mathrm{ml}$ L. rhamnosus GR-1, L. reuteri RC-14, or both strains together. The ratios of hyphae to blastospores in the cultures with or without $17 \beta$-estradiol were decreased in the presence of $\mathrm{H}_{2} \mathrm{O}_{2}$ or lactic acid as compared to the control group, but neither compound was able to prevent stimulation of hyphal germination by $17 \beta$-estradiol (Figure 8). Figure 8 also shows that the presence of L. rhamnosus GR-1 did not significantly influence the ratios of hyphae and blastospores nor was it able to prevent stimulation of hyphal germination by $17 \beta$-estradiol. The presence of $L$. reuteri $\mathrm{RC}-14$ significantly reduced the hyphae to blastospore ratio compared with the control containing $17 \beta$-estradiol, but not as compared with the untreated control. The presence of $L$. reuteri $\mathrm{RC}-14$, with or without $L$. rhamnosus GR-1, significantly reduced the ratio of hyphae to blastospores in the $17 \beta$-estradiol-treated group compared with the control group (Figure 8). These results suggest that $L$. reuteri RC-14, but not $L$. rhamnosus GR-1, inhibits $17 \beta$-estradiol-induced hyphal germination.

\section{Conclusions}

Protective effects on VK2 cells by L. rhamnosus GR-1 and $L$. reuteri $\mathrm{RC}-14$ were observed to be mediated directly against $C$. albicans, as well as by influencing VK2 cell responses in the present study. The lactobacilli produced soluble inhibitors of $C$. albicans growth including $\mathrm{H}_{2} \mathrm{O}_{2}$, which has previously been recognized as an inhibitor [7]. The $\mathrm{H}_{2} \mathrm{O}_{2}$ production by $17 \beta$-estradiol-induced $\mathrm{VK} 2$ cells in the latter study was of the same magnitude
A

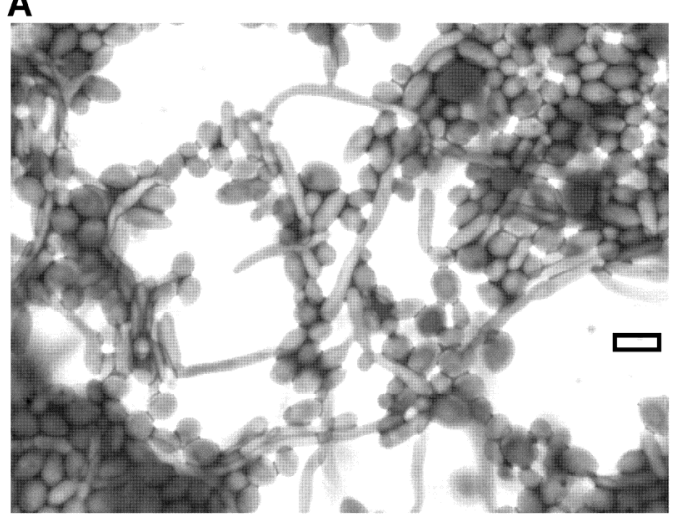

B

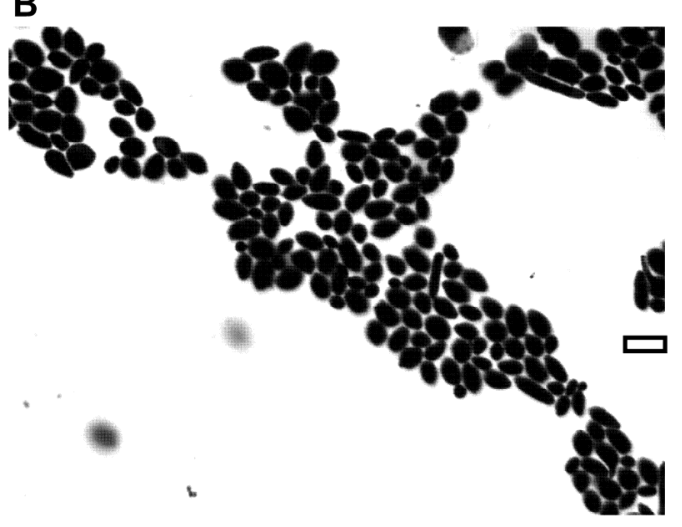

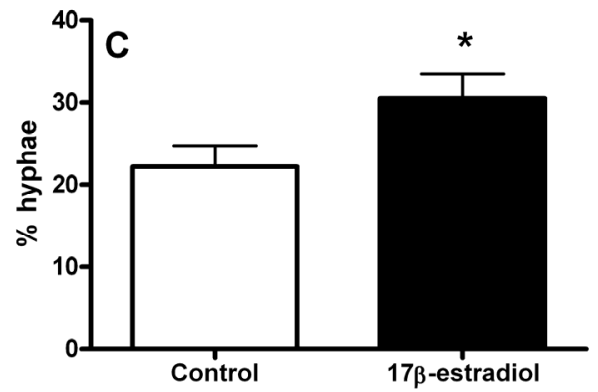

Figure 7. 17 $\beta$-estradiol affects the morphology of $C$. albicans. Addition of (A) $10 \mathrm{nM} 17 \beta$-estradiol to $C$. albicans cultures was associated with the presence of $32 \%$ hyphal forms compared with (B) $22 \%$ hyphal forms without $17 \beta$-estradiol. The images illustrate numbers of hyphae counted in 10 high power microscopic fields $(400 \times)$ of Gram-stained cultures. The rectangles in each image approximate a span of $10 \mu \mathrm{m}$. The average numbers $(C)$ of hyphae were compared as average \% hyphae from 10 high-power microscopic fields of Gram-stained slides from each of 6 groups of untreated and $10 \mathrm{nM} 17 \boldsymbol{\text { }}$-estradiol-treated cultures. *There were significantly more hyphae in $17 \beta$-estradiol-treated cultures than control cultures by the paired $T$-test, $\mathbf{P}<0.05$. 


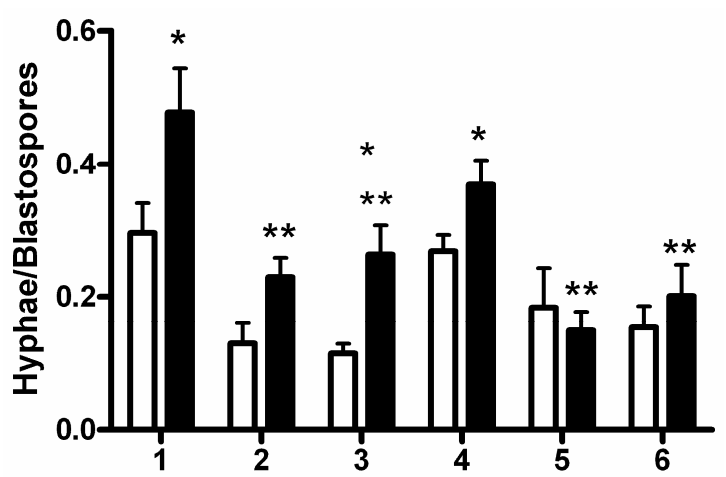

Figure 8. Effects of treatments on estrogen-induced hyphal germination. $C$. albicans was grown in GTS medium ( $\square$ ) without or ( $\square$ ) with $10 \mathrm{nM} 17 \beta$-estradiol and (1) untreated or treated with (2) $0.01 \mu \mathrm{g} / \mathrm{ml} \mathrm{H}_{2} \mathrm{O}_{2}$, (3) $2 \mu \mathrm{g} / \mathrm{ml}$ lactic acid, (4) $1 \times 10^{7} \mathrm{CFU} / \mathrm{ml}$ L. rhamnosus GR-1, (5) $1 \times 10^{7} \mathrm{CFU} / \mathrm{ml}$ L. reuteri RC-14, or (6) $1 \times 10^{7} \mathrm{CFU} / \mathrm{ml}$ L. rhamnosus GR-1 and $L$. reuteri $\mathrm{RC}-14$. Data are represented as the mean \pm standard error ratios of pseudohyphae to blastospores in $\mathbf{1 0}$ microscopic high-power $(400 \times)$ fields. *The results from the group cultured with $17 \beta$-estradiol is significantly different from the untreated group by the paired T-test, $P<0.05$. $* *$ The results from the treated group is significantly different than the results from the untreated control group by analysis of variance, $P<0.05$.

as $\mathrm{H}_{2} \mathrm{O}_{2}$ produced by the lactobacilli in the present study. Vaginal epithelial cells produce xanthine oxidase and superoxide dismutase, which can generate reactive oxygen intermediates, including $\mathrm{H}_{2} \mathrm{O}_{2}$ [21]. The ability of vaginal epithelial cells to produce anti-Candida mediators suggests that there are natural defenses already in place in the vaginal mucosa with further contributions by lactobacilli.

In the present study, the $\mathrm{pH}$ of the media was decreased in the presence of the lactobacilli, which is also known to be inhibitory to C. albicans [22]. While some of the $\mathrm{pH}$ lowering may have been due to lactobacilli, $17 \beta$-estradiol was also able to induce the VK2 cells to lower $\mathrm{pH}$ without lactobacilli. This phenomenon of estrogen-induced vaginal $\mathrm{pH}$ lowering has been explained as an increased regulation of a proton pump mechanism at the apical membrane surface of vaginal epithelial cells [22]. Apparently, the vaginal mucosa already exhibits some of the same mechanisms to suppress C. albicans that are expected from the lactobacilli.

In the present study, the lactobacilli also decreased the adherence of $C$. albicans to the VK2 cell monolayers, which may reduce $C$. albicans infectivity. The addition of $17 \beta$-estradiol to the media increased germination of $C$. albicans to hyphal forms, which may be a more infective morphology [12]. In the present study, more blastospores were observed in the presence of lactobacilli, suggesting that they can antagonize the effects of the hormone on $C$. albicans hyphal germination. The induction of C. albi- cans hyphal germination by $17 \beta$-estradiol was not significantly inhibited by $\mathrm{H}_{2} \mathrm{O}_{2}$, lactic acid, or L. rhamnosus GR-1, but was inhibited by $L$. reuteri RC-14. The latter strain has been shown to inhibit $C$. albicans growth [23]. Some Lactobacillus spp. strains produce $\mathrm{H}_{2} \mathrm{O}_{2}$ and bacteriosin-like molecules that work together to inhibit C. albicans growth [24]. Another product from L. reuteri RC-14 may account for its' ability to inhibit $C$. albicans germination, but it was not identified in the current study. Some strains of $L$. reuteri produce the antibiotic reuterin, but strain RC-14 does not [25].

$17 \beta$-estradiol can increase infectivity of $C$. albicans on vaginal epithelia by altering the structure of the tissue. Estrogen causes changes in the permeability of the vaginal epithelium through estrogen receptor $\alpha$ and an ERK-MAPK signaling cascade [26]. This increased permeability of the epithelium may be exploited by fungal hyphae to invade through the mucosal cell layer. In the present study, the presence of $17 \beta$-estradiol significantly reduced the TEER of $C$. albicans-infected VK2 cell monolayers without evidence of cell damage, which is consistent with the concept of increased epithelial permeability described in the latter study [26]. Other studies have shown growth of $C$. albicans is enhanced by the presence of $10 \mathrm{nM} 17 \beta$-estradiol [27]. The more effective suppression of $C$. albicans growth on agar inhibition tests by $L$. reuteri RC-14, compared with $L$. rhamnosus GR-1 supports this role of growth and germination inhibition for $L$. reuteri $\mathrm{RC}-14$.

In summary, this study shows that $C$. albicans infection of VK2 cells, a model of vaginal epithelial cells, can be inhibited by the VK2 cells themselves through production of $\mathrm{H}_{2} \mathrm{O}_{2}$ and acidification of the media, and probiotic L. rhamnosus GR-1 and $L$. reuteri $\mathrm{RC}-14$ provide additional support to this protective mechanism. The presence of $17 \beta$-estradiol induces infectivity of $C$. albicans by increasing growth and hyphal germination, which is not inhibited by $\mathrm{H}_{2} \mathrm{O}_{2}$, lactic acid, or L. rhamnosus GR-1 alone. The presence of $L$. reuteri RC-14 restricts these indicators of increased $C$. albicans infectivity by $17 \beta$-estradiol. This work helps explain why VVC symptoms emerge during times of increased estrogen levels in the vaginal tract and suggests a mechanism by which some probiotic lactobacilli can be protective against VVC. From a regulatory science viewpoint, we suggest that future probiotic bacterial strains be selected for their ability to limit $17 \beta$-estradiol-induced growth and hyphal germination by $C$. albicans.

\section{Acknowledgements}

This work was supported by funds from the Food and Drug Administration Office of Women's Health of the Public Health Service. The authors thank Dr. Mark Hart and 
Dr. Marli Azevedo for critical review of the manuscript. The opinions expressed in this manuscript are the authors' and do not necessarily reflect the position of the Food and Drug Administration.

\section{REFERENCES}

[1] M. E. Falagas, G. I. Betsi and S. Athanasiou, "Probiotics for Prevention of Recurrent Vulvovaginal Candidiasis: A Review," Journal of Antimicrobial Chemotherapy, Vol. 58, No. 2, 2006, pp. 266-272. doi:10.1093/jac/dk1246

[2] J. D. Sobel, "Vulvovaginal Candidosis," The Lancet, Vol. 369, No. 9577, 2007, pp. 1961-1971. doi:10.1016/S0140-6736(07)60917-9

[3] A. M. Cole, "Innate Host Defense of Human Vaginal and Cervical Mucosae," Current Topics in Microbiology and Immunology, Vol. 306, 2006, pp. 199-230. doi: $10.1007 / 3-540-29916-5 \quad 8$

[4] D. A. Eschenbach, S. S. Thwin, D. L. Patton, T. M. Hooton, A. E. Stapleton, K. Agnew, C. Winter, A. Meier and W. E. Stamm, "Influence of the Normal Menstrual Cycle on Vaginal Tissue, Discharge, and Microflora," Clinical Infectious Diseases, Vol. 30, No. 6, 2000, pp. 901-907. doi: $10.1086 / 313818$

[5] J. D. Sobel, "Does Lactobacillus Prevent Post-Antibiotic Vulvovaginal Candidiasis?" Current Infectious Disease Reports, Vol. 7, No. 6, 2005, pp. 443-444. doi:10.1007/s11908-005-0045-6

[6] G. Reid and A. W. Bruce, "Urogenital Infections in Women: Can Probiotics Help?" Postgraduate Medicine Journal, Vol. 79, No. 934, 2003, pp. 428-432. doi:10.1136/pmj.79.934.428

[7] M. A. Strus, A. Kucharska, G. Kukla, M. BrzychczyWłoch, K. Maresz and P. B. Heczko, "The in Vitro Activity of Vaginal Lactobacillus with Probiotic Properties Against Candida," Infectious Diseases in Obstetrics and Gynecology, Vol. 13, No. 2, 2005, pp. 69-75. doi:10.1080/10647440400028136

[8] S. Coudeyras, G. Jugie, M. Vermerie and C. Forestier, "Adhesion of Human Probiotic Lactobacillus rhamnosus to Cervical and Vaginal Cells and Interaction with Vaginosis-Associated Pathogens," Infectious Diseases in Obstetrics and Gynecology, Vol. 2008, 2008, pp. 1-5. doi: $10.1155 / 2008 / 549640$

[9] A. K. Ildgruben, I. M. Sjöberg and M.-L. K. C. Hammarström, "Influence of Hormonal Contraceptives on the Immune Cells and Thickness of Human Vaginal Epithelium," Obstetrics \& Gynecology, Vol. 102, No. 3, 2003, pp. 571-582. doi:10.1016/S0029-7844(03)00618-5

[10] W. Tarry, W., M. Fisher, S. Shen and M. Mawhinney, "Candida albicans: The Estrogen Target for Vaginal Colonization," Journal of Surgical Research, Vol. 129, No. 2, 2005, pp. 278-282. doi:10.1016/j.jss.2005.05.019

[11] C. R. Wira, K. S. Grant-Tschudy and M. A. Crane-Godreau, "Epithelial Cells in the Female Reproductive Tract: A Central Role as Sentinels of Immune Protection," American Journal of Reproductive Immunology, Vol. 53, No. 2, 2005, pp. $65-76$. doi:10.1111/j.1600-0897.2004.00248.x

[12] O. S. Kinsman and A. E. Collard, "Hormonal Factors in Vaginal Candidiasis in Rats," Infection and Immunity, Vol. 53, No. 3, 1986, pp. 498-504.

[13] A. Cassone, F. De Bernardis and G. Santoni, "Anticandidal Immunity and Vaginitis: Novel Opportunities for Immune Intervention," Infection and Immunity, Vol. 75, No. 10, 2007, pp. 4675-4686. doi:10.1128/IAI.00083-07

[14] M. L. Peterson, K. Ault, M. J. Kremer, A. J. Klingelhutz, C. C. Davis, C. A. Squier and P. M. Schlievert, "The Innate Immune System Is Activated by Stimulation of Vaginal Epithelial Cells with Sataphylococcus aureus and Toxic Shock Syndrome Toxin 1," Infection and Immunity, Vol. 73, No. 4, 2005, pp. 2164-2174 doi:10.1128/IAI.73.4.2164-2174.2005

[15] M. Schaller, K. Zakikhany, J. R. Naglik, G. Weindl and B. Hube, "Models of Oral and Vaginal Candidiasis Based on In Vitro Reconstituted Human Epithelia," Nature Protocols, Vol. 1, No. 6, 2006, pp. 2767-2773. doi:10.1038/nprot.2006.474

[16] C. Hollmer, M. Essmann, K. Ault and B. Larsen, "Aherence and Blocking of Candida albicans to Cultured Vaginal Epithelial Cells: Treatments to Decrease Adherence," Infectious Diseases in Obstetrics and Gynecology, Vol. 2006, 2006, pp. 1-6. doi:10.1155/IDOG/2006/98218

[17] A. M. Geshnizgani and A. B. Onderedonk, "Defined Medium Simulating Genital Tract Secretions for Growth of Vaginal Microflora," Journal of Clinical Microbiology, Vol. 30, No. 5, 1992, pp. 1323-1326.

[18] S. Al-Mushrif and B. M. Jones, "A Study of the Prevalence of Hydrogen Peroxide Generating Lactobacilli in Bacterial Vaginosis: The Determination of $\mathrm{H}_{2} \mathrm{O}_{2}$ Concentrations Generated in Vitro, by Isolated Strains and the Levels Found in Vaginal Secretions of Women with and without Infection," Journal of Obstetrics and Gynaecology, Vol. 18, No. 1, 1998, pp. 63-67. doi: $10.1080 / 01443619868325$

[19] H. Motulsky, "Intuitive Biostatistics," Oxford University Press, New York, 1995.

[20] R. A. Gaffney, M. F. Venegas, C. Kanerva, E. L. Navas, B. E. Anderson, J. L. Duncan and A. J. Schaeffer, "Effect of Vaginal Fluid on Adherence of Type 1 Piliated Escherichia coli to Epithelial Cells," The Journal of Infectious Diseases, Vol. 172, No. 6, 1995, pp. 1528-1535. doi:10.1093/infdis/172.6.1528

[21] R. Gossrau, W. M. Frederiks and C. J. F. van Noorden, "Histochemistry of Reactive Oxygen-Species (ROS)-Generating Oxidases in Cutaneous and Mucous Epithelia of Laboratory Rodents with Special Reference to Xanthine Oxidase," Histochemistry and Cell Biology, Vol. 94, No. 5, 1990, pp. 539-544. doi:10.1007/BF00272619

[22] G. I. Gorodeski, U. Hopfer, C. C. Liu and E. Margles, "Estrogen Acidifies Vaginal $\mathrm{pH}$ by Up-Regulation of Proton Secretion via the Apical Membrane of Vaginal-Ectocervical Epithelial Cells," Endocrinology, Vol. 146, No. 2, 2005, pp. 816-824. doi:10.1210/en.2004-1153

[23] R. C. R. Martinez, et al., "Effect of Lactobacillus rhamnosus GR-1 and Lactobacillus reuteri $\mathrm{RC}-14$ on the Ability of Candida albicans to Infect Cells and Induce In- 
flammation," Microbiology and Immunology, Vol. 53, No. 9, 2009, pp. 487-495.

doi:10.1111/j.1348-0421.2009.00154.x

[24] J. Kaewsrichen, K. Peeyananjarassri and J. Kongprasertkit, "Selection and Identification of Anaerobic Lactobacilli Producing Inhibitory Compounds Against Vaginal Pathogens," FEMS Immunology and Medical Microbiology, Vol. 48, No. 1, 2006, pp. 75-83. doi:10.1111/j.1574-695X.2006.00124.x

[25] P. Cadieux, et al., "Evaluation of Reuterin Production in Urogenital Probiotic Lactobacillus reuteri RC-14," Applied and Environmental Microbiology, Vol. 74, No. 15,
2008, pp. 4645-4649. doi:10.1128/AEM.00139-08

[26] X. Li, L. Y. Zhou and G. I. Gorodeski, "Estrogen Regulates Epithelial Cell Deformability by Modulation of Cortical Actomyosin through Phosphorylation of Nonmuscle Myosin Heavy-Chain II-B Filaments," Endocrinology, Vol. 147, No. 11, 2006, pp. 5236-5248. doi:10.1210/en.2006-0779

[27] X. Zhang, M. Essmann, E. T. Burt and B. Larsen, "Estrogen Effects on Candida albicans: A Potential VirulenceRegulating Mechanism," Journal of Infectious Disease, Vol. 181, No. 4, 2000, pp. 1441-1446. doi: $10.1086 / 315406$ 